\title{
CRÍTICA AO NACIONALISMO, À MODERNIDADE E AO POSITIVISMO EM TRISTE FIM DE POLICARPO QUARESMA
}

\section{CRITICISM OF NATIONALISM, MODERNITY AND POSITIVISM IN TRISTE FIM DE POLICARPO QUARESMA}

Resumo: Este artigo é fruto de uma avaliação conjunta das disciplinas de Teoria da História III e História Contemporânea I, ministradas na UFPR, no ano de 2019. O objetivo foi o de ter um melhor entendimento das relações de aspectos constituintes de diferentes sociedades ao longo do século XIX, através da leitura de uma obra ficcional. O livro por mim escolhido foi Triste Fim de Policarpo Quaresma, de Lima Barreto. Na parte inicial do artigo, são abordadas as possibilidades do estudo histórico através da Literatura. Em seguida, são introduzidos o enredo do livro e suas relações com a sociedade e as ideias da época. Ao fim, são apresentadas as considerações finais.

Palavras-chave: Triste Fim de Policarpo Quaresma; Nacionalismo; Positivismo; Modernidade; História e Literatura; Crítica.

Abstract: This article is the result of a joint assessment for the subjects Theory of History III and Contemporary History I, both given in UFPR, in 2019. The objective was to have a better understanding of the relations of constituent aspects from different societies during the nineteenth century, through the reading of a fictional work. The book chosen by me was Triste Fim de Policarpo Quaresma, from Lima Barreto. In the initial part of the article, the possibilities of the historical study through literature are approached. Next, the book's plot and its relations with society and with the ideas of that time are introduced. At the end, final remarks are presented.

\footnotetext{
${ }^{1}$ Graduando em História (Licenciatura e Bacharelado) pela Universidade Federal do Paraná. Email para contato: gabrielbrumperin@hotmail.com. Endereço para o Currículo Lattes: http://lattes.cnpq.br/2869727336592199.
} 
Keywords: Triste Fim de Policarpo Quaresma; Nationalism; Positivism; Modernity; History and Literature; Criticism.

\section{Introdução}

Ao se eleger a produção literária como documento histórico, deparamo-nos com a discussão da literatura como fonte histórica, visto que esse material, ao transitar entre a ficção e a realidade, permite-nos uma re-leitura dos aspectos e das semelhanças da realidade vivida numa temporalidade passada (...) (SILVEIRA, 2006: 117).

O objetivo do presente artigo será o de analisar uma obra literária, contextualizando-a em sua época de produção e examinando o ambiente que retrata. Dessa forma, tornar-se-á possível um entendimento mais amplo de vários aspectos políticos, sociais e culturais do período histórico representado.

As ficções literárias não são e nem buscam ser uma cópia da realidade. Os acontecimentos nelas inseridos devem ser tratados como verossímeis. O que está no romance - ou o que deixa de estar - é filtrado e escolhido de acordo com os sentimentos, com a imaginação e com as posições de quem o produz. Dessa forma, alguns acontecimentos do livro podem - por se tratar de um romance - não necessariamente ter ocorrido. No entanto, eles não deixam de refletir uma realidade em que o autor estava inserido, uma vez que uma das características de muitos romances é a verossimilhança. 
Analisar o romance é, portanto, uma forma de promover um entendimento das relações dos muitos aspectos constituintes das mais diversas sociedades. Além disso, o estudo da literatura traz novas possibilidades para se analisar o passado através da visão de sujeitos com menos visibilidade social, permitindo se conhecer uma versão que não apenas a dos documentos oficiais ou dos vencedores (SEVCENKO, 1993: 21). No que diz respeito à utilização da obra de Lima Barreto como fonte histórica, Sevcenko ressalta a amplitude de temas que o escritor abrange em sua produção literária. Sua obra abarcava "praticamente tudo o que de mais relevante oferecia a realidade de sua época" (SEVCENKO, 1993: 162). A literatura de Lima Barreto, portanto, desempenhou papel fundamental na historiografia brasileira, a exemplo da obra "A Revolta da Vacina: Mentes insanas em corpos rebeldes", do próprio historiador Nicolau Sevcenko, em que a produção literária do escritor carioca é essencial para a pesquisa desse tema. Nesse sentido, a prática de utilizar a literatura como fonte histórica é extremamente frutífera e torna possível a elaboração de diferentes e mais amplas visões de diversos contextos.

\section{Sobre o autor}

Afonso Henriques de Lima Barreto era neto de escravos, tendo nascido em 13 de maio de 1881. Sua mãe era professora primária e diretora; seu pai trabalhou como tipógrafo até o fim da década de $1880 \mathrm{em}$ jornais cariocas. A estréia de Lima Barreto na literatura se deu em 1909 com Recordações do Escrivão Isaías Caminha, obra que possui fortes 
características autobiográficas, retratando as desigualdades sociais e preconceitos raciais vivenciados pelo autor. Grande parte de sua produção é perpassada por esse tom autobiográfico, inclusive a obra que será aqui analisada. Acrescentando essa questão a todas as já citadas sobre a relação entre História e Literatura, analisar sua produção mostra-se um exercício ainda mais rico em face desse caráter de seus trabalhos. Triste Fim de Policarpo Quaresma vem a ser seu terceiro livro, publicado no final de 1915. Após sua morte, em 1922, teve várias obras publicadas, entre elas algumas de suas mais famosas, como Os Bruzundangas (1923) e Clara dos Anjos (1948).

\section{Sinopse da obra}

Policarpo Quaresma é um patriota idealista. Durante toda a obra, busca reformar a pátria brasileira e torná-la a maior do mundo. Na primeira parte do livro, busca fazê-lo pela cultura; na segunda parte, pela agricultura; na terceira e última, pela política. No entanto, durante a narrativa, os obstáculos que encontra vão desiludindo o personagem e desmistificando a imagem de uma pátria idealizada que uma vez tivera.

\section{Análise da obra}

O romance que será analisado é Triste Fim de Policarpo Quaresma, de Lima Barreto. Seu conteúdo foi inicialmente publicado em folhetins, em 1911, no Jornal do Commercio. Em 1915, a obra integral foi publicada em livro. Em sua leitura, podemos identificar que ela se passa na última década 
do século XIX no Rio de Janeiro. Alguns acontecimentos que a perpassam podem nos dar essa referência. Entre eles, a Revolução Federalista (1893-1895) e a Revolta da Armada (1893). Nesse período, a República ainda era muito incipiente, tendo sido proclamada em 1889. Em seus primeiros anos, ela passou por crises de legitimidade - a exemplo dos acontecimentos citados que, de formas semelhantes, contestavam-na.

\section{Crítica a teorias raciais}

Quanto a ex-escravizados, negros e mestiços - caso de Lima Barreto, a relação com a República tornava-se ainda mais conturbada à medida que a cidadania prometida a esses grupos pelo regime republicano não era consolidada. Oficialmente, a escravidão já havia acabado, porém sua herança ainda se fazia presente na sociedade. A raça determinava desigualdades, submissão, inferioridade. Lima Barreto retrata esse legado em suas obras, denunciando as diversas expressões do racismo na sociedade.

Para sua legitimação, essas ideias precisavam de discursos, de teorias. Nesse contexto, do fim do século XIX e início do século XX, são inúmeras as teorias que buscavam justificar a subordinação racial e, por conseguinte, legitimar o racismo. Sob a influência de Herbert Spencer, Hippolyte Taine e Cesare Lombroso, autores brasileiros defendiam teses de eugenia, visando a um branqueamento da população, que poderia acontecer através da imigração de europeus. Entre eles estão Nina Rodrigues, Sílvio Romero e Euclides da Cunha (NATAL, 2017: 236-237). No próprio enredo 
do livro de Lima Barreto, na biblioteca de Policarpo Quaresma havia obras de Charles Darwin, autor da teoria do evolucionismo que influenciou o já citado Herbert Spencer.

$\mathrm{Na}$ obra, há passagens que explicitam de que forma esse racismo estava presente na sociedade. Ricardo Coração dos Outros - personagem do livro, amigo de Quaresma - era tocador de modinhas. Seu principal instrumento era o violão, que, naquela época, não era bem visto pela população. Ricardo possuía grande popularidade e fazia sucesso onde era requisitado. Em certo momento, um crioulo também tocador de modinhas começa a rivalizar com ele. Ricardo vê sua ascensão com maus olhos, uma vez que - por ser negro e pelo preconceito que o cercava - contribuiria para aumentar o desprestígio do violão (BARRETO, 2001: 74). Quanto à presença negra na obra, há vários personagens ex-escravos retratados. Isso mostra que naquele período não havia apenas pessoas que conviviam com o legado da escravidão, mas também pessoas que haviam sentido na pele a própria escravidão. Em outra passagem, podemos observar Lima Barreto projetando no protagonista Policarpo suas ideias e sua crítica a essas teorias. No contexto em que Quaresma observava um de seus empregados, Mané Candeeiro - que era negro -, cantando, o autor afirma que "Quaresma procurou descobrir nele aquela odiosa catadura que Darwin achou nos mestiços; mas, sinceramente, não a encontrou" (BARRETO, 2001: 120).

A questão da imigração também está presente na obra. Vicente Coleoni, pai da afilhada de Quaresma, é um imigrante italiano. A visão de 
Quaresma acerca do incentivo que o Governo dava aos imigrantes é negativa. Segundo ele, o governo os dava benefícios sem se importar com os que aqui já estavam, os brasileiros (BARRETO, 2001: 118). Isso pode ser interpretado como uma crítica do autor ao uso da imigração enquanto meio para o branqueamento da sociedade - com influência das teorias eugenistas. Essa passagem também deve ser entendida como demonstração do nacionalismo de Quaresma, que buscava valorizar o brasileiro em detrimento do que vinha de fora.

\section{Nacionalismo}

Normalmente a Nação é concebida como um grupo de pessoas unidas por laços naturais e portanto eternos - ou pelo menos existentes ab immemorabili - e que por causa desses laços, se torna a base necessária para a organização do poder sob a forma do Estado nacional (BOBBIO, 1998: 796).

Esses laços se configurariam através de grupos que teriam em comum determinadas características, como a língua, os costumes, a religião, o território, etc. Isso seria necessário para a consolidação de uma identidade nacional que desse coesão à nação e à pátria. A definição de Lima Barreto de patriotismo ia de encontro a isso. Segundo ele, esse patriotismo estava ligado a "um sentimento criado pelos líderes de Estado, sentimentos guerreiros de agressão, ou seja, o patriotismo estaria ligado à violência, à luta entre povos do mundo quando ele diz respeito à defesa." (PAURA, 2010: 4) O contexto em que o escritor viveu nos ajuda a entender 
essa visão. Em seu período de vida (1881-1922), houve diversas guerras e conflitos, tanto a nível nacional quanto internacional. Só na década em que Triste Fim de Policarpo Quaresma é ambientado - 1890 - tivemos, a nível interno, a Revolta Federalista e a Revolta da Armada. Mais tarde em sua vida, Barreto presenciou também a Primeira Guerra Mundial (1914 1918). Ou seja, ele viveu um contexto em que o nacionalismo estava em voga - e muitas vezes era utilizado para legitimar essas guerras. Essa explicação é essencial para entendermos de que modo esse cenário tem influência na forma como o autor retrata o nacionalismo na obra aqui analisada.

O espírito nacionalista de Policarpo Quaresma é o fio condutor do livro. Ele é um patriota exaltado e idealista. Durante o enredo, o personagem busca conduzir a nação brasileira a vôos mais altos, elevando-a a uma das maiores do mundo. Na primeira parte do livro, busca fazê-lo pela cultura, pelos costumes. Nessa parte começam a ser delineadas ideias que vão introduzindo ao leitor o ufanismo nacionalista de Quaresma.

Quaresma vive com sua irmã, Adelaide, em São Januário, no Rio de Janeiro. Desejara ser militar, mas não tendo sido aceito por insuficiência física, contentou-se com a administração, também no meio militar. Possuía uma vasta biblioteca na qual privilegiava autores nacionais, entre eles Gregório de Matos, Gonçalves Dias e José de Alencar. Os dois últimos eram da geração romântica. Podemos encontrar algumas características semelhantes entre suas obras e as ações de Quaresma. Entre elas, a exaltação do índio e o nacionalismo. Em uma atitude que mescla essas duas 
características, Quaresma propôs que o tupi-guarani fosse a língua oficial do país. Seu argumento era de que o índio seria ainda intocado pela cultura do colonizador e, dessa forma, o portador da cultura genuína brasileira.

Seu requerimento, no entanto, foi recebido às gargalhadas; sua ideia, tida como absurda. Jornais publicavam ilustrações que debochavam do Major Quaresma e de sua proposta. Na repartição, local onde trabalhava, eram vários os comentários acerca de seu ato. Não se importou tanto com os comentários chamando-o de louco quanto com os que afirmavam ser ele um ignorante no que diz respeito à língua tupi. Esses o fizeram furioso. Preocupado em provar que era profundo conhecedor do tupi, dividiu-se entre suas obrigações diárias e entre mostrar que sabia a outra língua. Certo dia, Quaresma estava redigindo um documento oficial, quando ouviu um comentário insinuando que ele não soubesse tupi. De forma inconsciente, começou a traduzir o documento para o idioma indígena. Quando seu chefe soube que havia sido ele quem fizera aquilo, chamou-o para sua sala. $\mathrm{Na}$ conversa que tiveram, Quaresma foi reprimido por seu ato e suspenso da repartição. Esse primeiro revés sofrido pelo Major começa a dar indícios da posição de Lima Barreto acerca da ideia de pátria, que será explicitamente revelada ao final do livro.

Depois desse episódio, Quaresma passa a viver em um hospício. Iam visitá-lo apenas sua afilhada - Olga -, o pai dela e Ricardo. Após o período em que lá passou, ele saiu triste, deprimido. Conviver com a loucura o fez ter uma fisionomia de desgosto. Voltou à sua casa, mas isso não bastou para livrar-lhe daquela tristeza. Um dia, em uma conversa, sua afilhada the deu a 
ideia de comprar um sítio para praticar o cultivo. Olga era uma das pessoas que buscava entendê-lo. Apesar de achar algumas das decisões de seu padrinho pouco usuais, ela não o julgava.

Sua presença na obra, assim como a de outras mulheres, evidencia o papel feminino na sociedade daquela época. Quando de seu casamento, Olga não o fez necessariamente por gostar do homem que seria seu marido. “Casava por hábito de sociedade, um pouco por curiosidade e para alargar o campo de sua vida e alargar a sensibilidade" (BARRETO, 2001: 71). Em muitos casos a principal função da vida da mulher nessa época era a do casamento. A representação de Ismênia - filha do general vizinho de Quaresma - na obra gira em torno de seu casamento e suas angústias acerca dele. Havia toda uma pressão em seu entorno para que se casasse, sempre que a viam perguntavam-na quando se casaria. A forma que a sociedade via o casamento e coagia as mulheres a ele pode ser exemplificada nesse trecho: “(...) naquela obrigação que incrustam no espírito das meninas, que elas se devem casar a todo custo, fazendo do casamento o pólo e fim da vida, a ponto de parecer uma desonra, uma injúria ficar solteira" (BARRETO, 2001: 171). No entanto, há também casos que fogem à regra, como o da irmã de Quaresma, que, com mais de 50 anos, nunca quis e nunca se casou.

A sugestão de mudar-se para um sítio trouxe-lhe esperança e reavivou nele ideias que por um tempo haviam ficado adormecidas. Assim tem início a segunda parte do livro, que trata de quando Quaresma passa a morar no sítio de nome "Sossego". Ele vê nessa empreitada a possibilidade 
de demonstrar como eram férteis e fecundas as terras brasileiras. “(...) o que era principal à grandeza da pátria estremecida, era uma forte base agrícola, um culto pelo seu solo ubérrimo, para alicerçar fortemente todos os outros destinos que ela tinha de preencher" (BARRETO, 2001: 83).

Nesse trecho, Policarpo é a representação do pai de Lima Barreto, João Henriques, afirma Lilia Schwarcz (NATAL, 2017: 238). Ele escrevia artigos sobre as terras férteis do Brasil, colocando a agricultura como vocação do país. Essas ideias são encarnadas pelo personagem do romance. Não somente as ideias, mas também os atos de ambos convergem. Assim como Quaresma, o pai do autor compra e se muda para um sítio. Outro fato em comum é o de os dois terem enlouquecido - sendo esse mais um exemplo do caráter autobiográfico da obra de Lima Barreto.

\section{Elementos românticos: a crítica à modernidade}

Essa mudança de ares do personagem demonstra, analisada mais amplamente, uma crítica à ideia de modernidade e à civilização capitalista. Löwy e Sayre definem o romantismo como uma visão de mundo histórica (LÖWY; SAYRE, 1993: 18-19). Chamam atenção para sua multiplicidade de definições, características e aspectos constituintes. A definição por eles dada, no entanto, elenca um elemento em comum: o do romantismo como crítica da modernidade. Ele se opõe à realidade capitalista moderna. Essa crítica se daria em nome de valores ideais de um passado pré-capitalista. Um local em que essa modernidade teria pouco chegado, que teria ainda elementos de tempos pré-capitalistas - e é frequentemente tema de 
romances - é o campo. É a esse lugar que Quaresma vai em busca de uma fuga da modernidade.

Como é que toda a gente queria ser empregado público, apodrecer numa banca (...)? Como é que se preferia viver em casas apertadas, sem ar, sem luz, respirar um ambiente epidêmico, sustentar-se de maus alimentos, quando se podia tão facilmente obter uma vida feliz, farta, livre, alegre e saudável?

E era agora que ele chegava a essa conclusão, depois de ter sofrido a miséria da cidade e o emasculamento da repartição pública, durante tanto tempo! Chegara tarde, mas não a ponto de que não pudesse antes da morte travar conhecimento com a doce vida campestre e a feracidade das terras brasileiras (BARRETO, 2001: 83).

A vida no campo é descrita como doce. A cidade é associada à miséria. O trem - elemento que comumente é retratado como símbolo da modernidade - é também mencionado: "O major pensou ainda um pouco como aquilo (trem) era bruto e feio, e como as invenções do nosso tempo se afastam tanto da linha imaginária da beleza que os nossos educadores de dois mil anos atrás nos legaram" (BARRETO, 2001: 83). Nessa passagem podemos identificar a busca pelo antigo, por algo que se perdeu com a modernidade. Não só no campo, mas também em sua gente, Quaresma via "a existência de um resíduo forte da nossa nacionalidade a resistir às invasões das modas e gostos estrangeiros" (BARRETO, 2001: 89). As invasões seriam sinais da modernidade, sinais de uma cidade cada vez mais cosmopolita. 
O personagem é também anti-cosmopolita, ao opor-se ao grande crescimento populacional da cidade e à entrada de produtos estrangeiros. Muitas vezes seu patriotismo e sua crítica à modernidade aparecem juntos. É o caso de sua negação à entrada de manufaturados estrangeiros e da defesa do violão - instrumento que seria a expressão característica da alma nacional - em detrimento do piano, instrumento da cultura burguesa moderna. Dessa forma, vemos no personagem de Policarpo uma recusa, uma crítica a elementos modernos, e uma procura pelo simples, pelo campo.

Essa busca de Quaresma, no entanto, não lhe traz bons frutos. Todo o conhecimento adquirido nos livros e todos os equipamentos utilizados não lhe foram úteis. Seu ajudante, o ex-escravo Anastácio, mostrou-lhe que era preciso apenas saber lidar com a terra, com a natureza, não havendo necessidade de seus sofisticados aparelhos. Nesse episódio há um embate entre a teoria e a prática. $\mathrm{O}$ conhecimento empírico do homem da região (Anastácio) funcionava muito melhor do que as teorias dos livros de Quaresma e as utilidades de seus equipamentos. Não desistindo de sua tarefa, Quaresma dedica-se incansavelmente às suas culturas, mas todo seu esforço não é páreo para um pequeno inimigo que vem aos montes. O sítio é invadido por formigas. Elas danificam sua plantação, levam grande parte de suas reservas e deixam-no desiludido de seus sonhos de erguer e melhorar a pátria pela agricultura. As formigas simbolizam os inimigos do país, que impedem suas aspirações de melhora. Com o fim da segunda parte do livro vem também o segundo fracasso de Quaresma. "Em lugar da 
terra ubérrima, vamos encontrar uma terra invadida por formigas; aquela terra paradisíaca só existe nos livros, esta na realidade”. (SANTIAGO, 1982: 180).

\section{Crítica à República e ao Positivismo}

Já abatido pelos reveses que sofrera, certo dia Policarpo leu no jornal que os navios da esquadra haviam se insurgido e exigiam a renúncia do presidente. Era a Revolta da Armada. Com esperança, ele decide deixar de lado suas culturas e ir ao Rio de Janeiro ajudar as tropas do Presidente Floriano Peixoto. Assim inicia a terceira parte do livro. Lá chegando, o autor descreve a cidade com um clima tenso. As pessoas tomavam cuidado ao falar umas com as outras, qualquer crítica ou fala suspeita era motivo para ser perseguido. A perseguição era democrática - poderia acontecer tanto com os mais pobres quanto com os mais abastados e influentes. Lima Barreto denuncia, dessa forma, o autoritarismo da República e de Floriano Peixoto - citando-o como ditador. Sua concepção de governo seria o de uma tirania doméstica. $\mathrm{O}$ autor associa-o ao positivismo e, por conseguinte, faz uma crítica a essa corrente.

Eram os adeptos desse nefasto e hipócrita positivismo, um pedantismo tirânico, limitado e estreito, que justificava todas as violências, todos os assassínios, todas as ferocidades em nome da manutenção da ordem, condição necessária, lá diz ele, ao progresso (...) (BARRETO, 2001: 132). 
Dessa forma, o autor mostra-se contrário à noção positivista de progresso, que seria alcançada pela ordem. Esses ideais, de ordem e progresso, estão estampados em nossa bandeira. Foi com a proclamação da República que se passou a usar a bandeira nacional tal qual a concebemos atualmente, com os dizeres "Ordem e Progresso". Isso mostra como esse ideal positivista estava diretamente relacionado com o novo regime. A crítica ao positivismo, portanto, apresenta-se também como uma crítica à República, ao presidente, e à própria pátria. Barreto descreve Floriano como desprovido de qualidades intelectuais e preguiçoso, o que o impedia de ser considerado um homem forte comparado a grandes chefes de Estado. A visão de Quaresma e muitos outros, no entanto, não era essa. Via-o como um ídolo político, fino, tenaz e supervidente. Além disso, Policarpo era leitor do historiador positivista Fustel de Coulanges. Admirava, portanto, tanto a República quanto o positivismo.

No primeiro encontro dos dois, o presidente o trata com indiferença, fazendo pouco caso com um manuscrito que lhe havia sido entregue por Quaresma. Nesse manuscrito, estavam sugestões e ideias para acabar com os males do Brasil e melhorar o país. Em um segundo encontro, o personagem pede ao Marechal se já havia lido seu memorial. A resposta é afirmativa. No entanto, o presidente não leva a sério suas ideias, e refere-se a ele como um visionário. $\mathrm{O}$ abatimento e os questionamentos que esses acontecimentos lhe trazem são registrados numa carta à irmã. Nela, Quaresma afirma ser incompreendido. Pensa que todo seu sacrifício fora inútil e mostra-se desiludido com a política e, de forma geral, com a vida. 
No fim do livro, de forma arbitrária, ele é preso pelo próprio regime que havia defendido, pelo próprio presidente que havia admirado, e pela própria pátria que havia exaltado.

\section{Considerações finais}

Ao final, Quaresma se desilude com a nação que tanto defendera. Sua vida fora norteada por uma ilusão, um conceito falso - a pátria. Referindo-se a ela, o autor cita que "Certamente era uma noção sem consistência racional e precisava ser revista" (BARRETO, 2001: 93). A obra revela-se, portanto, como uma crítica à ideia de pátria e à sua defesa incondicional. O fim de Quaresma, personagem que encarna o nacionalismo, é melancólico. Despediu-se do mundo "sem deixar traço seu, sem um filho, sem um amor, sem um beijo mais quente, sem nenhum mesmo, e sem sequer uma asneira!" (BARRETO, 2001: 93). Analisando o desfecho da obra, podemos interpretar o nome do personagem - Policarpo - como uma ironia, segundo Silviano Santiago (SANTIAGO, 1982: 173). "Policarpo" significa "que produz, que dá muitos frutos". No entanto, com o trecho citado fica claro que isso não é o que acontece com Quaresma, que nada deixa de si. "Carpo" significa pulso, e também pode ser associado ao verbo carpir, limpar o mato. "O Policarpo é de triste fim porque é de nenhum fruto e é também de pulso fraco, e é ainda um idealista que não consegue limpar a erva ruim de sua plantação" (SANTIAGO, 1982: 174).

Triste fim de Policarpo Quaresma nos traz uma percepção mais rica de aspectos sociais, políticos e culturais de sua época de produção. Pode ser 
interpretado, conforme feito no presente artigo, como uma crítica ao nacionalismo cego e ufanista, à modernidade, às teorias raciais e à jovem República positivista. Através da obra, podemos tanto desvendar ideias do autor como ideias em voga no período, e de que forma a sociedade se relacionou com elas - ou aceitando-as, ou criticando-as.

\section{Referências}

BARRETO, Lima. Triste fim de Policarpo Quaresma. São Paulo: Ateliê Editorial, 2001.

BOBBIO, Norberto; MATEUCCI, Nicola; PASQUINO, Gianfranco. Dicionário de política. Brasília: Editora Universidade de Brasília, $11^{\mathrm{a}}$ ed., 1998.

BORGES, Valdeci Rezende. História e Literatura: Algumas Considerações. Revista de Teoria da História. Goiânia, v. 3, n. 1, p. 94-109, 2010. Disponível em: <https://www.revistas.ufg.br/teoria/article/view/28658>. Acesso em: 19 fev. 2021.

BORGES, Valdeci Rezende. Policarpo Quaresma e o Romantismo Anticapitalista. Revista do Niesc. Goiânia, v. 1, p. 78-89, maio. 2001. Disponível em: <www.academia.edu/11320213/Policarpo_Quaresma_e_o_Romantismo_A nticapitalista>. Acesso em: 19 fev. 2021.

LÖWY, Michael; SAYRE, Robert. Romantismo e Politica. Rio de Janeiro: Paz e Terra, 1993.

NATAL, Caion Meneguello. O triste visionário: Lima Barreto e seu tempo. Revista do Instituto de Estudos Brasileiros, São Paulo, n. 68, p. 235-240, dez. 2017. Disponível em: $<$ http://www.scielo.br/pdf/rieb/n68/2316-901X-rieb-68-00235.pdf $>$ Acesso em: 19 fev. 2021. 
PACHECO, Keli C. Policarpo Quaresma: do triste fim ao prêmio. Revista Uniletras. Ponta Grossa, v. 29, p. 141-157, 2007. Disponível em: $<$ www.revistas2.uepg.br/index.php/uniletras/article/view/178/177>. Acesso em: 19 fev. 2021.

PAURA, Rômulo Rafael Ribeiro. Patriotismo em Lima Barreto: uma visão pelas crônicas. In: XIV ENCONTRO REGIONAL DA ANPUH - RIO: MEMÓRIA E PATRIMÔNIO, 2010, Rio de Janeiro. Anais Eletrônicos. Rio de Janeiro: UniRio, 2010. p. 1 - 9 Disponível em: $<$ http://www.encontro2010.rj.anpuh.org/resources/anais/8/1276739214_AR QUIVO_ANPUH-RomuloPaura.pdf>. Acesso em: 19 fev. 2021.

SANTIAGO, Silviano. Uma ferroada no peito do pé. In: . Vale quanto pesa: ensaios sobre questões político-culturais. Rio de Janeiro: Paz e Terra, 1982. pp. 163-183.

SEVCENKO, Nicolau. A Revolta da Vacina: Mentes insanas em corpos rebeldes. São Paulo: Scipione, 2003.

SEVCENKO, Nicolau. Literatura como missão: Tensões sociais e criação cultural na $1^{\text {a }}$ República. 2a . ed. São Paulo: Brasiliense, 1993.

SCHWARCZ, Lilia Moritz. Lima Barreto: triste visionário. São Paulo: Cia. das Letras, 2017.

SILVEIRA, Cristiane da. Entre a História e a Literatura: A identidade nacional em Lima Barreto. HISTÓRIA: questões \& debates, Curitiba, ano 23, n. 44, p. 115-145, jan./jun. 2006.

SOUZA, Renato Dias de. As representações do nacionalismo em Lima Barreto. 2017, 259 f. Tese (Doutorado em Sociologia) - Universidade Federal de Goiás, Goiânia, 2017.

Recebido em: 18/08/2019 Aceito em: 20/02/2021 